\title{
Seasonal diversity of the bacterial communities associated with petroglyphs sites from the Negev Desert, Israel
}

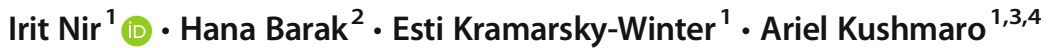

Received: 13 January 2019 / Accepted: 8 August 2019 / Published online: 17 August 2019

(C) Università degli studi di Milano 2019

\begin{abstract}
Rock art sites in the form of petroglyphs are found in the Negev Desert in southern Israel. These petroglyph sites include thousands of images depicting the life and culture of people in the region over the years. As they are part of the desert environment, these petroglyphs are exposed to natural and anthropogenic weathering processes. In natural rock sites, it is known that climatic conditions influence weathering and biofilm community development (Friedmann in Orig Life 10:223-235, 1980; $\mathrm{Li}$ et al. in PloS one 11:(9),163-287, 2016) Therefore, in order to develop tools for preservation and remediation, it is imperative to ascertain possible seasonal diversity of surface-inhabiting bacterial communities. To do so, we undertook to study and characterize the microbial communities inhabiting the rock sites during winter and summer. Next-generation sequencing (NGS) technologies using 16S rRNA gene were implemented on rock-surface slab samples to identify the microbial communities. 16S rRNA gene sequencing data revealed the presence of five main bacterial phyla, among them Actinobacteria, Cyanobacteria, Proteobacteria, Bacteroidetes, and Chloroflexi across the analyzed sites. The predominant phylum was Cyanobacteria (10-60\% relative abundance), followed by Actinobacteria (20-60\% relative abundance), Proteobacteria (5$35 \%)$, Bacteroidetes $(0.02-35 \%)$, and Chloroflexi (1-12\%). There was no significant difference in the bacterial diversity between samples from winter and summer. Five main phyla were observed in samples from the two seasons, winter (December) 2017 and summer (July) 2018. This study provides an important first step in understanding the possible seasonal dynamic of bacterial communities associated with the petroglyphs.
\end{abstract}

Keywords Petroglyphs $\cdot$ Bacteria $\cdot$ Cyanobacteria $\cdot$ Biofilm $\cdot$ Negev Desert

Electronic supplementary material The online version of this article (https://doi.org/10.1007/s13213-019-01509-z) contains supplementary material, which is available to authorized users.

Ariel Kushmaro

arielkus@bgu.ac.il

1 Department of Biotechnology Engineering Avram and Stella Goldstein-Goren, Ben-Gurion University of the Negev, P.O.B. 653, 8410501 Beer-Sheva, Israel

2 Unit of Environmental Engineering, Ben-Gurion University of the Negev, Beer-Sheva, Israel

3 National Institute of Biotechnology in the Negev, Ben-Gurion University of the Negev, Beer-Sheva, Israel

4 The Ilse Katz Center for Meso and Nanoscale Science and Technology, Ben-Gurion University of the Negev, Beer-Sheva, Israel

\section{Introduction}

The Negev Desert, situated in southern Israel, extends from the Sinai Desert region in the west to the Jordanian Arabian Desert in the east, covering approximately $13,000 \mathrm{~km}^{2}$ (Fig. 1). The Negev Desert contains various cultural heritage landscapes and archeological remains, and among them, hundreds of petroglyphs sites. These sites, can be found spread throughout the Negev central highlands, and are considered as a unique cultural landscape. The petroglyphs are carved on the local Eocene and late Cretaceous limestone rocks (Evenari et al. 1982) that are covered with thin dark coatings (Fig. 1). The petroglyph sites include thousands of figurative images, geometric shapes, symbols, and inscriptions. The use of archeological dating techniques revealed that these engravings are from around $3000 \mathrm{BCE}$. Recently, as more sites are being revealed, there has been an increasing awareness of their importance as a valuable cultural heritage resource (EisenbergDegen 2012). Unfortunately, despite the increase in the public 
Fig. 1 a Location of the Negev Desert in the south part of Israel. $\mathbf{b}$ Har Michya Petroglyph site in the Negev highlands arid zone. c View of the rock art site at Har Michya ( $\left.30^{\circ} 49^{\prime} \mathrm{N}, 34^{\circ} 43^{\prime} \mathrm{E}\right)$. d Rock engraving: the hunter, Har Michya
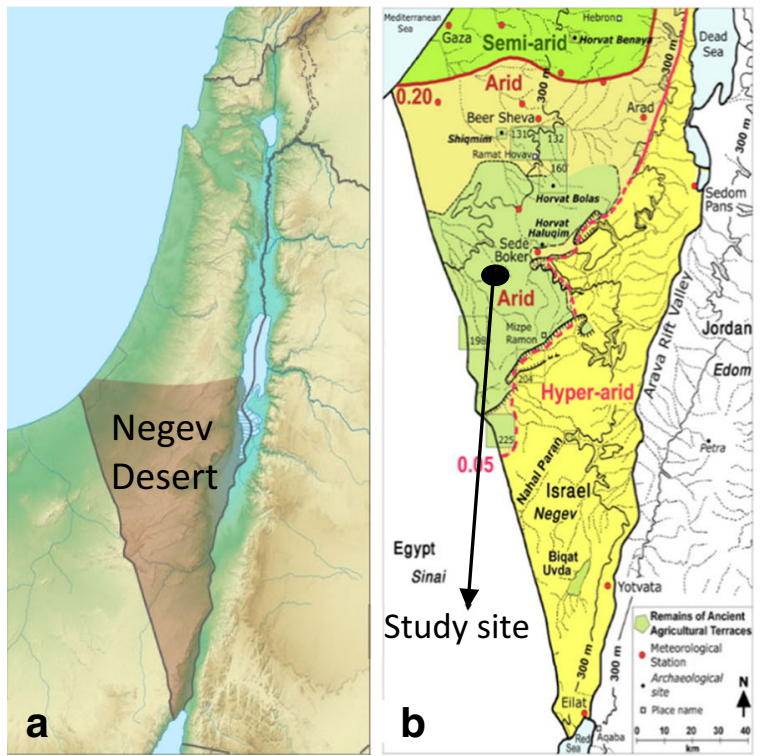

c

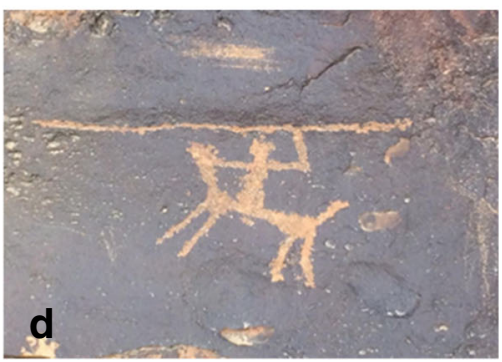

interest, there is an increase in physical damage caused by vandalism to the petroglyph sites. In addition, since they are part of the natural Negev Desert environment, the petroglyphs are exposed to natural weathering processes. Physical weathering processes such as diurnal heating and cooling of rock surfaces, chemical weathering processes, and weathering induced by biological agents such as plants, lichens, and bacteria may all affect their preservation state. Various groups of bacteria and other microorganisms inhabit rocks and stones in desert environments. Despite the inhospitable conditions of extreme deserts, several microhabitats have been established that are most suitable for life. One such microhabitat consists of the pores and fissures inside rocks (endolithic growth) and the rock underside (hypolithic growth) where humidity may be maintained. These endolithic habitats may offer microorganism better moisture conditions and shelter from harmful environmental factors (Golubic et al. 1981; Gorbushina 2007; Wierzchos et al. 2012). In general, microbial colonization is initiated by various phototrophic microorganisms (e.g., cyanobacteria, algae), which support further colonization by various heterotrophic and chemoautotrophic as bacteria and fungi. A vast number of studies revealed their composition diversity and structure under different environmental conditions (Danin 1999; Thulani et al. 2015; Gorbushina 2007; Smith et al. 2014; Villa et al. 2016; Chimienti et al. 2016; Li et al. 2016). Regarding hot desert environments, several studies have indicated that the endolithic communities comprise relatively simple communities dominated by cyanobacteria, with some heterotrophic components. It was found that in such communities, Archaea and Eukaryotes may be absent or present in low abundance (Büdel et al. 2004; Thulani et al. 2015; Wierzchos et al. 2012). Despite the vast number of publications regarding microbial communities inhabiting rock and stone monuments, to date, research focusing on interactions between climatic factors and bacterial communities specific to the petroglyphs sites in arid environment is still sparse. We, therefore, decided to investigate the rock microbial diversity during two seasons: the relatively wet winter (2017) and the dry summer (2018). Results from this study will provide insights into the diversity and complexity of the rock microbial communities and will likely contribute to the development of basic tools for preservation management of the rock art sites in the Negev Desert.

\section{Materials and methods}

\section{Study site}

The study site, Har Michya petroglyph park, is located in the central highlands of the Negev Desert (Fig. 1). Har Michya is situated 2-3 km west of the Byzantine town of Avdat in the central Negev $\left(30^{\circ} 49^{\prime} \mathrm{N}, 34^{\circ} 43^{\prime} \mathrm{E}\right)$ This area is regarded as an arid desert zone (Fig. 1) and receives an average of 80 $100 \mathrm{~mm}$ of rainfall annually mostly during the winter season. This is followed by a 3- to 5-month dry summer period (Hillel 1982) (Table S1). There are about 200 nights of dew/year providing abundant sources of liquid water for microbial lithobiontic colonization in this desert (Kidron 1999). All rock art found within this area, 965 panels with 5077 elements, have been previously documented (Eisenberg-Degen 2012).

\section{Sampling}

Sampling was carried out during winter (December) 2017 and summer (July) 2018 from identical rock types that were found adjacent to the petroglyphs at a distance of about $1 \mathrm{~m}$ from them (Fig. 2). Small slabs of weathered rock surface $2 \mathrm{~cm} \times$ 

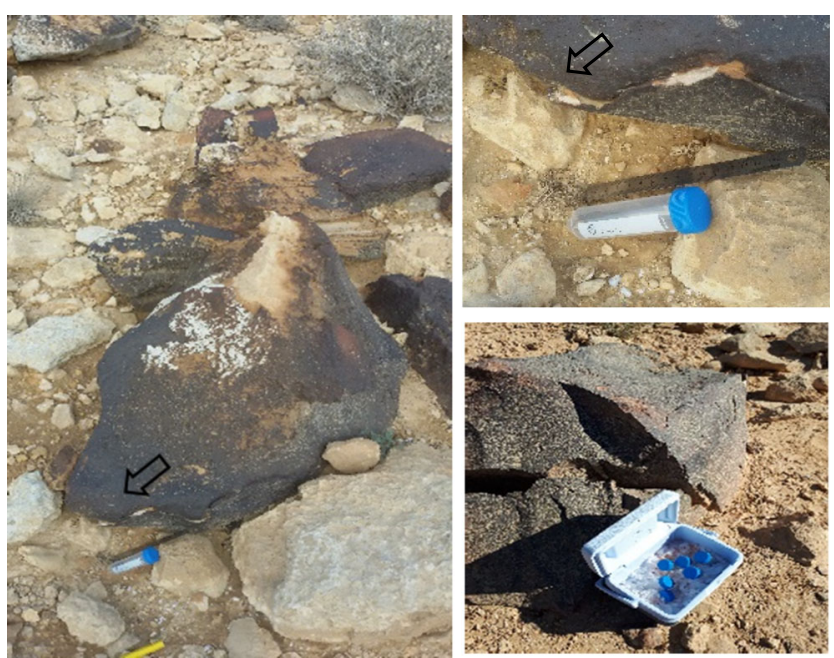

Fig. 2 Rock surface sampling, petroglyphs park, Har Michya, Negev Desert, Israel

$2 \mathrm{~cm}$ in size were collected aseptically using a small sterile chisel. All the samples were obtained from the rock surface containing the dark coating layer as well as the bright bedrock. The stone samples were each placed in separate sterile test tubes (Fig. 2). During winter 2017, the group of samples included samples from opposite faces of the rocks. These were marked as samples C1.1, C1.2, C2.1, C2.2, C3.1, C3.2, C7.1, and $\mathrm{C} 7.2$. Four more samples were collected randomly and were marked as C4, C5, C6, and C8. Sample C6 was collected from a nearby rock that lacks macroscopically visible dark coating. In the summer (July) of 2018, four more samples were collected randomly from rocks at the same site by a similar procedure as described previously and were marked as $112,122,132$, and 142 . The samples were transferred to the laboratory in a cooler box and were stored at $-20{ }^{\circ} \mathrm{C}$ until processing.

\section{Culture independent study: 16S rRNA gene sequencing}

Total genomic DNA from the environmental samples was extracted from $0.5 \mathrm{~g}$ of crashed stone samples using the MoBio PowerSoil DNA isolation kit (MoBio Laboratories. Inc., Carlsbad, CA, USA) following the protocol supplied by the manufacturer. The extracted DNA was submitted to the DNA Services Facility (DNAS), at the Research Resources Center, at the University of Illinois at Chicago (UIC) for bacterial small subunit (16S) ribosomal RNA (rRNA) gene sequencing using the Illumina MiSeq platform. Before sequencing, two steps of PCR amplification were performed. During the first PCR, fragments of the V3-V4 regions of the bacterial 16S rRNA gene were amplified using 341F/806R universal primers attached with $5^{\prime}$ linker sequences, CS1, and CS2 (known as common sequence 1 and 2).
The primer-linkers sequences were 5'-ACAC TGACGACATGGTTCTACACTACGGGAGGCAGC AGTGGG $(\mathrm{CS} 1341 \mathrm{~F}$; forward primer) and 5'-TACG G T A G C A G A G A C T T G G T C T G G A C TACHVHHHTWTCTAAT (CS2_806R; reverse primer). An additional PCR reaction was performed for library preparation (Green et al. 2015).

\section{S rRNA gene sequencing analysis}

Raw sequences reads were merged using the software package PEAR (Zhang et al. 2013) (v0.9.10). Low-quality sequences and chimeras were removed by the software package Mothur (Schloss et al. 2009) (v1.36.1).

The quality-controlled sequences were processed with the Quantitative Insights into Microbial Ecology (QIIME v1.9.1) package (Caporaso et al. 2010).

Briefly, sequence data were clustered into operational taxonomic units (OTU) at $97 \%$ similarity using UCLUST. Representative sequences from each OTU were extracted and aligned using PyNAST with a percent identity threshold of $60 \%$ to the Silva $16 \mathrm{~S}$ rRNA bacterial database.

\section{Statistical analysis}

Alpha and beta diversity, including the observed species index, the community richness (Chao1) and diversity (Shanon and Simpson indices), principal coordinate analysis (PCoA), and ANOSIM statistical test were calculated for all samples using Quantitative Insights into Microbial Ecology (QIIME v1.9.1) package (Caporaso et al. 2010) (Tables S2 and S3, Fig. 4).

\section{Climate data}

Data regarding mean maximum and minimum air temperature, highest maximum air temperature, lowest minimum air temperature, monthly average precipitation $(\mathrm{mm})$, and relative humidity $(\mathrm{RH})$ was obtained from the local Sde-Boker Meteorology Station $\left(30^{\circ} 87^{\prime} \mathrm{N}, 34^{\circ} 79^{\prime} \mathrm{E}\right)$ which is located about $10 \mathrm{~km}$ from the study site (source: Israel Meteorological Service) (Table S1).

\section{Results}

The results presented here provide initial insights into the structure and diversity of the microbial communities associated with the rock engravings panels during two seasons: winter 2017 and summer 2018. 


\section{Diversity analysis}

From a total of 646,138 raw sequences reads that were obtained, an average number of 40,383 reads per sample passed the quality control set of sequence filters mentioned above, with mean lengths of about 450 base pairs.

The rarefaction analysis allowed comparison of speciesrichness (number of OTUs) between different rock samples. Rarefaction curves approached saturation after about 1500 sequences, suggesting that the majority of the operational taxonomic units (OTUs) were recovered in this study (Fig. 3).

The alpha diversity was estimated based on the observed species, Chaol, Shannon and Simpson indices and reflected the community diversity and species richness of each sample (Table S2). The observed species score of the bacterial communities ranged from 275 to 575 for winter samples and 527 741 for summer samples while the Chao 1 index score ranged from 320 to 725 for winter samples and 590 to 886 for summer samples. According to these two indices, the samples obtained at summer reflected relatively higher bacterial richness. The Shannon scores ranged from 5.42 to 6.6 for the winter samples and from 5.93 to 6.6 for the summer samples. The Simpson scores ranged from 0.87 to 0.97 for the winter samples and 0.92 to 0.95 for the summer samples indicating that summer samples had relatively higher bacterial diversity. Nevertheless, these differences were not statistically significant.

Beta diversity analysis implementing principal coordinate analysis (PCoA) is presented in Fig. 4. The unweighted UniFrac distances show that compositions of these samples were clustered in two different groups, suggesting a difference between the two season samples. The weighted distances display a partial overlap between season samples. ANOSIM statistical test (Table S3) showed $P$ value of $82 \%$ and $R$-value of -0.14 for the different season samples. Therefore, it was

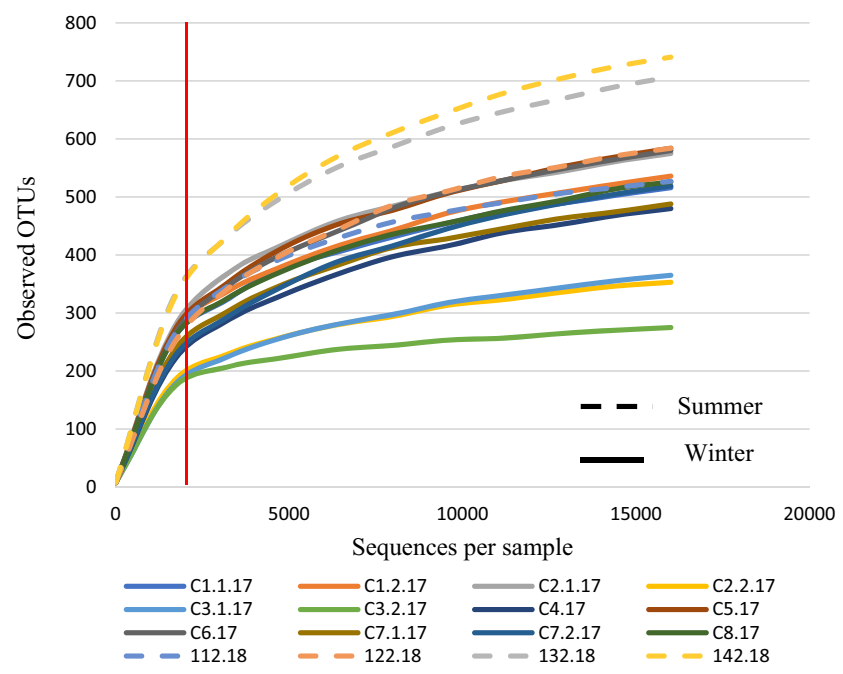

Fig. 3 Rarefaction curves of observed OTUs from rock samples: summer 2017 and winter 2018 demonstrated in this study that there was no significant difference in diversity between samples from winter 2017 and summer 2018. Thus, seasonal differences seem not to affect the bacterial communities' relative abundance but rather their composition (Table 1).

\section{Taxonomy overview}

DNA sequencing data revealed the presence of five main bacterial phyla, namely Cyanobacteria, Actinobacteria, Proteobacteria, Bacteroidetes, and Chloroflexi, across the analyzed sites. These main phyla were observed in samples from both winter and summer (Fig. 5, Table 1). All together, these phyla compromise about $85-95 \%$ of the rocks surface bacterial communities.

The predominant phylum was Cyanobacteria (10-60\% relative abundance) followed by the Actinobacteria phylum (20$60 \%$ relative abundance), mainly represented by the orders Frankiales $(0.02-38 \%)$ and Rubrobacterales $(1-42 \%)$. These phyla were followed by the Proteobacteria phylum (5-35\%) represented by the class Alphaproteobacteria (5-22\%), the Bacteroidetes phylum $(0.02-35 \%)$ represented by the order Cytophagales (0.4-2\%) and then followed by the Chloroflexi phylum (1-12\%). Within the Geodermatophilales order, members of the genus Blastococcus, Geodermatophilus, and Modestobacter were identified. The order Rubrobacterales was represented by the genus Rubrobacter. The phylum Cyanobacteria included members of the genus Chroococcidiopsis and of the genus Microcoleus. In addition, our study revealed approximately eight additional phyla, albeit at much lower percentages. These included DeinococcusThermus, Acidobacteria, Gemmatimonadetes, Planctomycetes, Firmicutes, Nitrospirae, and Verrucomicrobia. Five percent of the winter reads and 2.5\% of the summer reads were unassigned (Fig. 5).

\section{Discussion}

This study provides insights into the diversity and structure of the bacterial community associated with rock engraving sites at the Negev Desert (Israel) during two climatic different seasons. The winter is characterized by an average temperatures ranging from $14.8-19.1{ }^{\circ} \mathrm{C}$ during the day and $-3.6-0{ }^{\circ} \mathrm{C}$ at night and by relative humidity of $68-77 \%$. The summer is characterized by an average temperature ranging from 28.7 $32.7{ }^{\circ} \mathrm{C}$ during the day and $5.5-12.5{ }^{\circ} \mathrm{C}$ during night and relative humidity of $49-65 \%$ (Table $\mathrm{S} 1$ ).

Culture-independent methods implementing Illuminabased deep sequencing were used in order to gain a broader understanding of these communities. Rarefaction curves of observed taxonomic units (OTUs) confirmed that implementing these methods revealed most of the taxonomic 
Fig. 4 Unweighted (left) and weighted (right) principal coordinate analysis (PCoA) of the bacterial communities in winter (squares) and summer samples (dots)

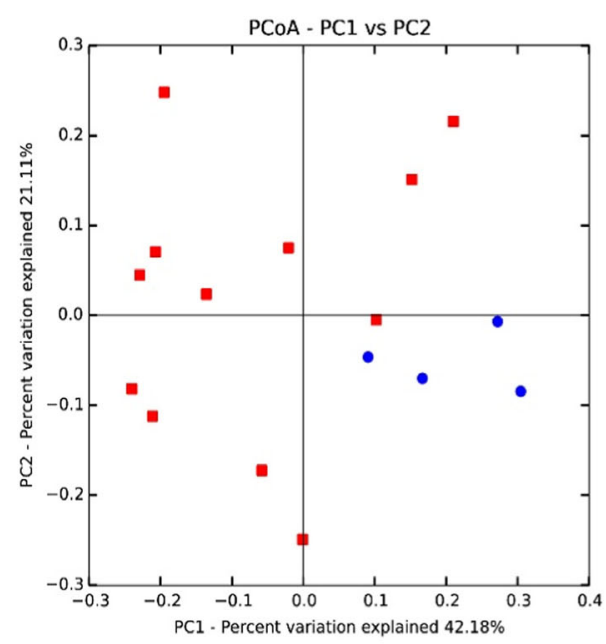

data from all of the rock samples studied at the two seasons (Fig. 3). The analysis of the metagenome samples revealed five major phyla as the most common components of the microbiota at the sites studied during both seasons. These five main phyla were Actinobacteria, Cyanobacteria, Proteobacteria, Bacteroidetes, and Chloroflexi. Some phyla though present a marked variation in summer and in winter, as Actinobacteria, Proteobacteria, Bacteroidetes, and Chloroflexi, which are more abundant in winter (Table 1). Indeed, some phyla among them, Deinococcus-Thermus, Acidobacteria, Gemmatimonadetes, Planctomycetes, Firmicutes, Nitrospirae, and Verrucomicrobia, were found at much lower percentages in the samples (Fig. 5). Cyanobacteria were detected in all samples and are one of the major components of the bacterial communities, accounting for an average of $50 \%$ of all bacterial phyla obtained during the summer, and an average of $30 \%$ of all phyla reads obtained during winter. Cyanobacteria are already known as common photoautotroph bacteria inhabiting soil and rock surfaces in a wide variety of terrestrial habitats in hot and cold desert crusts (Friedmann 1980; Krumbein and Jens 1981; Wierzchos et al. 2006; Dong et al. 2007). These organisms are considered as primary producers and generally adapted to resist adverse conditions due to their thick cell wall and the presence of protective pigments. Thus, the higher light levels

Table 1 Relative abundances of main bacterial phyla associated with the rock engraving panels

\begin{tabular}{lll}
\hline Phylum & $\begin{array}{l}\text { Relative abundance (\%) } \\
\text { Winter sampling }\end{array}$ & $\begin{array}{l}\text { Relative abundance (\%) } \\
\text { Summer sampling }\end{array}$ \\
\hline Actinobacteria & $17-58$ & $23-37$ \\
Cyanobacteria & $10-61$ & $44-61$ \\
Proteobacteria & $5-35$ & $4-10$ \\
Bacteroidetes & $1-35$ & $0.02-2.5$ \\
Chloroflexi & $2-12$ & $0.07-5$ \\
\hline
\end{tabular}

during summer may accelerate their colonization (Chrispim and Gaylarde 2005; Li et al. 2016; Chimienti et al. 2016). All this may explain their relatively higher abundance as was detected in our study in summer samples. For example, in our study, the Cyanobacteria was represented by the radiation-resistant Chroococcidiopsis sp., a genus that is frequently detected in stone monuments and rock sites in desert climatic zones as well as in Mediterranean climatic zones and beyond (Friedmann 1980; Büdel et al. 2004). The relative abundance of the Cyanobacteria in the summer samples may be either the result of more abundant Cyanobacteria or may be a result of the relatively lower abundance of other bacterial components as for example, Actinobacteria, in the rocks. It is likely that the presence and growth of many of the heterotrophic bacterial groups are dependent on their adaptation to high temperature and irradiance and low humidity. The heterotrophic Actinobacteria phylum detected in all the samples accounted for an average of $33 \%$ of the winter season bacterial communities and of $29 \%$ of the summer communities and are therefore considered in this study to be the second largest member of the bacterial communities. Members of this phylum were detected as a dominant bacterial taxon in subterranean environments in stone and rock cultural heritage sites in other geographic areas (Urzì et al. 2001). The Actinobacteria were also detected in several outdoor environments ( $\mathrm{Li}$ et al. 2016). An explanation for the high fraction of Actinobacteria could be due to their strong cell walls and their capability for forming spores, characteristics that may allow their survival in harsh environments. In our study, the Actinobacteria were represented mainly by members of the orders Geodermatophilales (represented by the genera Geodermatophilus, Blastococcus, and Modestobacter) and by the order Rubrobacterales (represented by the genus Rubrobacter). These taxa were already known from previous studies regarding stone monuments and rock sites (Urzì et al. 2001; Li et al. 2016) indicating their ability to resist adverse environmental conditions such as ultraviolet light, ionizing 
Fig. 5 Bacterial phylum level taxonomic comparison between samples collected from the petroglyphs sites at two seasons: winter 2017 and summer 2018 (implementing 16S rRNA gene sequencing)

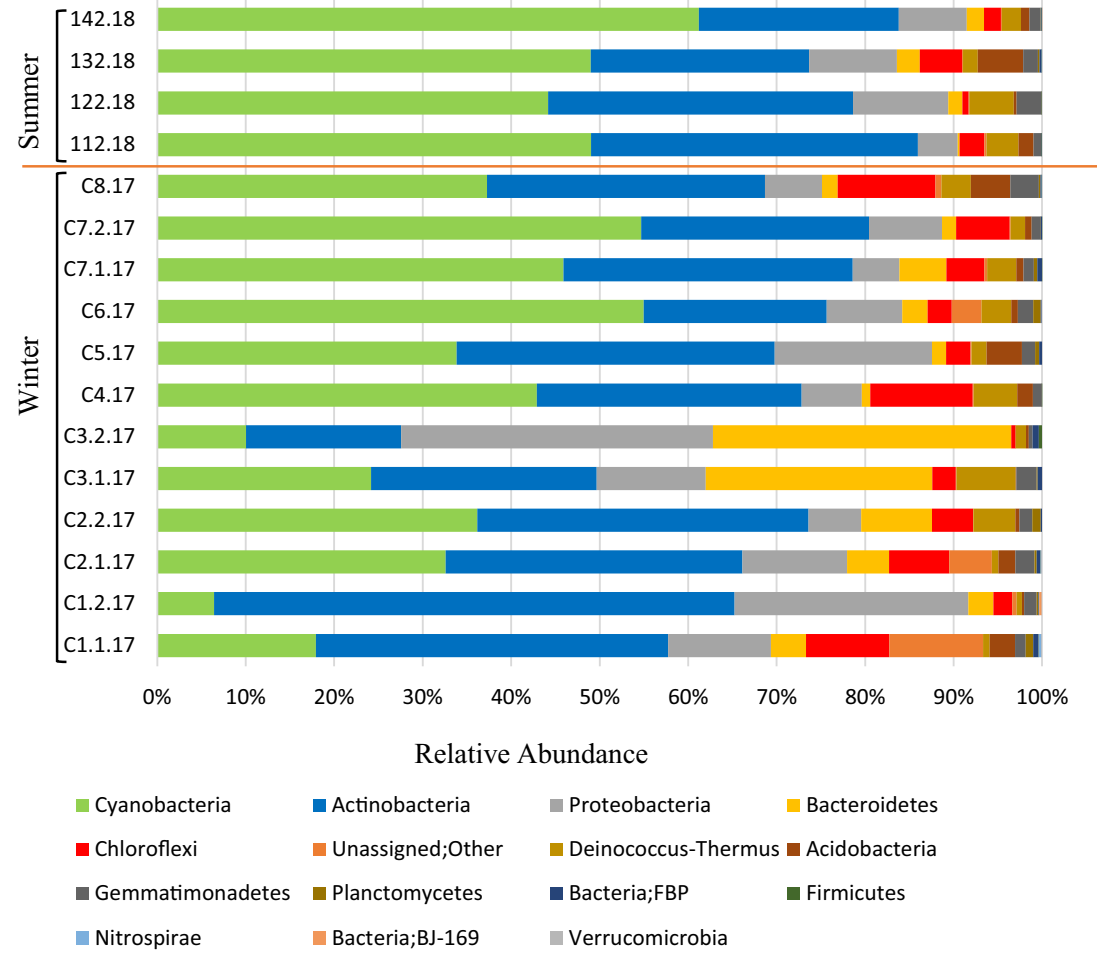

radiation, desiccation, and heavy metals. Similarly molecularly diverse group of the Actinobacteria genus Rubrobacter was reported in Australian dry soil (Chanal et al. 2006). Actinobacteria have also been found on the surface of the ancient sculptures in Yungang (Yan et al. 2012). Thus, the fact that Actinobacteria was found as one of the dominant phylum in the present study is not surprising especially when taking into account their competitive advantages such as their capacity for sporulation, their wide metabolic capacities, and their UV repair mechanisms (Thulani et al. 2015). A third major group, members of the phylum Proteobacteria, was detected in all samples and accounted for a mean of $13 \%$ of all winter season bacterial phyla and a mean of $8 \%$ of all summer phyla. This phylum was represented by the Alphaproteobacteria, Betaproteobacteria, and Gammaproteobacteria orders. Interestingly, these groups have been found in other rock sites from a wide geographic range, including the Atacama Desert and Black Canyon (Northup et al. 2010; Kuhlman et al. 2008). Other differences between summer and winter microbial diversity included differences in relative numbers of the members of the Chloroflexi phylum. They accounted for a mean of $6.6 \%$ of all winter season samples and a mean of $2.5 \%$ of all summer season samples. Members of this phylum were originally thought to live only in extreme environments such as hot springs but have been reported in temperate and even cold environments (Costello and Schmidt 2006). Indeed, they were also detected in rock varnish microbial community from the Yungay region of the Atacama Desert as well as rock varnish from the Black Canyon (Kuhlman et al. 2008 and Northup et al. 2010). Some of the other taxa that were found in the present study were found in low abundance and present unique adaptation mechanisms to extreme environments. One example is given by the members of the order Deinococcales of the bacterial phylum DeinococcusThermus. These bacteria have thick cell walls and unique resistance to exposure to high doses of gamma and UV radiation. This resistance to environmental hazards represents a trait of Terrabacteria, a well-supported phylogenetic group composed of Actinobacteria and four other major lineages of eubacteria (Firmicutes, Cyanobacteria, Chloroflexi, and Deinococcus-Thermus) that are assumed to colonize land and terrestrial environment billions of years ago. A study of an arid soil collected from the Sonoran Desert yielded 60 strains of the genus Deinococcus that were subsequently assigned to nine novel species (Rainey et al. 2005). This strengthens the premise that the rock surfaces may be considered an oligotrophic substrate. The arid climate appears to put some selective environmental pressure limiting the diversity of the microbial communities and enabling the survival of specific organisms adapted to these arid zone conditions. When examining the abundance of the bacterial communities during the different seasons at all taxonomy levels, a great deal of similarity between the two season samples was observed. Principal coordinate $(\mathrm{PCOA})$ indices and ANOSIM test results pointed out that there were no significant differences in bacterial diversity between the winter and summer samples (Fig. 4, Table S3). This may be explained by the fact that rock varnish and the surface layers play a role as shelter from the 
extreme environment conditions, enabling stable living conditions (Golubic et al. 1981; Wierzchos et al. 2012). Thus, our findings present initial insights into specific bacterial communities adapted to the climatic conditions and the specific petrographic characteristics.

\section{Conclusion}

Our results demonstrated that implementing next-generation sequencing (NGS) methods provides access to a larger group of bacterial taxa and therefore is an important first step in the study of the microorganisms inhabiting the rock art sites. In the present study, we showed that although differences were found between seasons, they were not significant. Furthermore, there was not a significant difference in the diversity of the taxa across samples from both seasons though there was a difference in richness and abundance. Future investigation of the presence and distribution of microbiota at higher taxonomic levels (e.g., genus or species level) will likely provide a deeper understanding of possible differences in diversity during summer and winter. We therefore suggest that further study implementing microclimatic measurements of the rock habitat will expand our knowledge regarding the influence of environmental factors on the diversity and functionality of the bacterial communities.

Acknowledgements The Israel antiquity authorities (IAA) is acknowledged for their cooperation in this project.

\section{Compliance with ethical standards}

Conflict of interest The authors declare that they have no conflict of interest.

Research involving human participants and/or animals This article does not contain any studies with human participants or animals performed by any of the authors.

Informed consent Informed consent was obtained from all individual participants included in the study.

\section{References}

Büdel B, Weber B, Kühl M, Pfanz H, Sültemeyer D, Wessels D (2004) Reshaping of sandstone surfaces by cryptoendolithic cyanobacteria: bioalkalization causes chemical weathering in arid landscapes. Geobiology 2(4):261-268

Caporaso JG, Kuczynski J, Stombaugh J, Bittinger K, Bushman FD, Costello EKHuttley G.A (2010). QIIME allows analysis of highthroughput community sequencing data. Nat Methods 7(5): 335336

Chanal A, Chapon V, Benzerara K, Barakat M, Christen R, Achouak W, Barras F, Heulin T (2006) The desert of Tataouine: an extreme environment that hosts a wide diversity of microorganisms and radiotolerant bacteria. Environ Microbiol 8:514-525
Chimienti G, Piredda R, Pepe G (2016) Profile of microbial communities on carbonate stones of the medieval church of San Leonardo di Siponto (Italy) by Illumina-based deep sequencing. Appl Microbiol Biotechnol 100:8537

Chrispim CA, Gaylarde CC (2005) Cyanobacteria and biodeterioration of cultural heritage: a review. Microb Ecol 49(1):1-9

Costello EK, Schmidt SK (2006) Microbial diversity in alpine tundra wet meadow soil: novel Chloroflexi from a cold, water-saturated environment. Environ Microbiol 8(8):1471-1486

Danin A (1999) Desert rocks as plant refuge in the near east. Bot Rev 2(65):95-167

Dong H, Rech JA, Jiang H, Sun H, Buck BJ (2007) Endolithnic cyanobacteria in soil gypsum: occurences in Atacama (Chile), Mojave (United States), and Al-Jafr Basin (Jordan) Deserts. J Geophys Res 112:G02030. https://doi.org/10.1029/2006JG000385

Eisenberg-Degen D (2012). Rock art of the central Negev: documentation, stylistic analysis, chronological aspects, the relation between rock art and the natural surroundings, and reflections on the mark makers society through the Art. Ph.D. Thesis, Ben-Gurion University of the Negev, Beer-Sheba

Evenari M, Shanan L, Tadmor N (1982) The Negev: the challenge of a desert. Harvard University Press

Friedmann EI (1980) Endolithic microbial life in hot and cold deserts. Orig Life 10:223-235

Golubic SE, Friedmann I, Schneider J (1981) The lithobiontic ecological niche, with special reference to microorganisms. J Sediment Res 51(2):475-478. https://doi.org/10.1306/212F7CB6-2B24-11D7$8648000102 \mathrm{C} 1865 \mathrm{D}$

Gorbushina AA (2007) Life on the rocks. Environ Microbiol 9(7):16131631. https://doi.org/10.1111/j.1462-2920.2007.01301.x

Green SJ, Venkatramanan R, Naqib A (2015) Deconstructing the polymerase chain reaction: understanding and correcting bias associated with primer degeneracies and primer-template mismatches. PLoS One 10(5):122-128

Hillel D (1982) Negev land, water, and life in a desert environment. Prager, New York

Kidron GJ (1999) Altitude dependent dew and fog in the Negev Desert, Israel. Agriculture Forest Meteorology 96:1-8

Krumbein WE, Jens K (1981) Biogenic rock varnishes of the Negev desert (Israel): an ecological study of iron and manganese transformation by cyanobacteria and fungi. Oecologia 50:25-38

Kuhlman KR, Venkat P, La Duc MT, Kuhlman GM, McKay CP (2008) Evidence of a microbial community associated with rock varnish at Yungay, Atacama Desert, Chile. J Geophys Res Biogeosci 113(G4)

Li Q, Zhang B, He Z, Yang X (2016) Distribution and diversity of bacteria and fungi colonization in stone monuments analyzed by highthroughput sequencing. PLoS One 11(9):163-287

Northup DE, Snider JR, Spilde MN, Porter ML, van de Kamp JL, Boston PJ, Bargar JR (2010) Diversity of rock varnish bacterial communities from Black Canyon, New Mexico. J Geophys Res Biogeosci 115(G2)

Rainey FA, Ray K, Ferreira M, Gatz BZ, Nobre MF, Bagaley D, Small AM (2005) Extensive diversity of ionizing-radiation-resistant bacteria recovered from Sonoran Desert soil and description of nine new species of the genus Deinococcus obtained from a single soil sample. Appl Environ Microbiol 71(9):5225-5235

Schloss PD, Westcott SL, Ryabin T, Hall JR, Hartmann M, Hollister B, Sahl JW (2009) Introducing mothur: open-source, platform-independent, community-supported software for describing and comparing microbial communities. Appl Environ Microbiol 7(23):75377541. https://doi.org/10.1007/s00248-016-0770-4

Smith HD, Baqué M, Duncan AG, Lloyd CL, McKay CP, Billi D (2014) Comparative analysis of cyanobacteria inhabiting rocks with different light transmittance in the Mojave Desert: a Mars terrestrial analogue. Int J Astrobiol 13(3):271-277 
Thulani P, Makhalanyane A, Valverde E, Gunnigle A, Frossard JB, Ramond D, Cowan A (2015) Microbial ecology of hot desert edaphic systems. FEMS Microbiol Rev 39(2):203-221

Urzì C, Brusetti L, Salamone P, Sorlini C, Stackebrandt E, Daffonchio D (2001) Biodiversity of Geodermatophilaceae isolated from altered stones and monuments in the Mediterranean basin. Environ Microbiol 3(7):471-479

Villa F, Stewart SP, Klapper I, Jacob MJ, Cappitelli F (2016) Subaerial biofilms on outdoor stone monuments: changing the perspective toward an ecological framework. BioScience 66:285-294. https:// doi.org/10.1093/biosci/biw006

Wierzchos J, Ascaso C, Mckay CP (2006) Endolithic cyanobacteria in halite rocks from the hyperarid core ofthe Atacama Desert. Astrobiology 6:1-7. https://doi.org/10.1089/ast.2006.6.415
Wierzchos J, de los Ríos A, Ascaso C (2012) Microorganisms in desert rocks: the edge of life. Earth International Microbiology 15:171-181

Yan F, Ge Q, Li Q, Yu M, Zhu X, Pan J (2012) Analysis of microbial community on the surface of the historic stone and nearby rock samples in Yungang Grottoes. Acta Microbiol Sin 52(5):629-636

Zhang J, Kobert K, Flouri T, Stamatakis A (2013) PEAR: a fast and accurate Illumina paired-end read merger. Bioinformatics 30(5): 614-620

Publisher's note Springer Nature remains neutral with regard to jurisdictional claims in published maps and institutional affiliations. 